Article

\title{
Assessment and Comparison of TMPA Satellite Precipitation Products in Varying Climatic and Topographic Regimes in Morocco
}

\author{
Adam Milewski ${ }^{1, *}$, Racha Elkadiri ${ }^{2}$ and Michael Durham ${ }^{1}$ \\ 1 Water Resources \& Remote Sensing Group (WRRS), Department of Geology, University of \\ Georgia, 210 Field Street, 306 Geography-Geology Building, Athens, GA 20602, USA; \\ E-Mail: durham@uga.edu \\ 2 Department of Geosciences, Western Michigan University, 1903 W. Michigan Avenue, \\ 1187 Rood Hall, Kalamazoo, MI 49008, USA; E-Mail: rachaelkadiri@gmail.com \\ * Author to whom correspondence should be addressed; E-Mail: milewski@uga.edu; \\ Tel.: +1-706-542-2652; Fax: +1-706-542-2425.
}

Academic Editors: Richard Gloaguen and Prasad S. Thenkabail

Received: 20 February 2015 / Accepted: 24 April 2015 / Published: 5 May 2015

\begin{abstract}
TRMM Multi-satellite Precipitation Analysis (TMPA) satellite precipitation products have been utilized to quantify, forecast, or understand precipitation patterns, climate change, hydrologic models, and drought in numerous scientific investigations. The TMPA products recently went through a series of algorithm developments to enhance the accuracy and reliability of high-quality precipitation measurements, particularly in low rainfall environments and complex terrain. In this study, we evaluated four TMPA products (3B42: V6, V7temp, V7, RTV7) against 125 rain gauges in Northern Morocco to assess the accuracy of TMPA products in various regimes, examine the performance metrics of new algorithm developments, and assess the impact of the processing error in 2012. Results show that the research products outperform the real-time products in all environments within Morocco, and the newest algorithm development (3B42 V7) outperforms the previous version (V6), particularly in low rainfall and high-elevation environments. TMPA products continue to overestimate precipitation in arid environments and underestimate it in high-elevation areas. Lastly, the temporary processing error resulted in little bias except in arid environments. These results corroborate findings from previous studies, provide scientific data for the Middle East, highlight the difficulty of using TMPA products in varying conditions, and present preliminary research for future algorithm development for the GPM mission.
\end{abstract}


Keywords: TMPA; precipitation; remote sensing; Morocco; arid environments; 3B42 V7

\section{Introduction}

Precipitation is one of the most important meteorological forcing parameters in hydrological investigations and land surface modeling, yet it is largely unknown or misused in water budgets and hydrologic models due to the lack of field-based monitoring systems that are required to estimate precipitation, runoff, and recharge [1-8]. Fortunately, recent advances in remote sensing have shown promise in addressing these inadequacies [9-15]. Satellite remote sensing datasets have been increasingly employed as an ancillary source of essential hydrologic measurements used for understanding and modeling hydrologic fluxes. The use of satellite precipitation data from various satellite sensors, missions, and algorithms (e.g., Tropical Rainfall Measuring Mission (TRMM), Special Sensor Microwave Imager (SSM/I), Climate Prediction Center Morphing Algorithm (CMORPH)) in scientific investigations has been on the rise due to the general paucity or unavailability of adequate rain gauge data for the majority of the Earth's surface and their higher degree of accuracy due to algorithm development (e.g., TMPA V5-V7). As a result, TRMM satellite products are widely being used in many parts of the world and particularly in the Middle East and North Africa (MENA) region [11,16-19].

One of the most widely used satellite-based precipitation products utilized is the TRMM Multi-satellite Precipitation Analysis (TMPA) [20]. The TMPA algorithm has evolved over the past few years by merging a variety of existing ground- and satellite-based observations to yield high spatial $(0.25 \times 0.25$ degree $)$ and temporal resolution (three-hourly instantaneous retrievals) observations with a higher degree of accuracy [20]. The two types of TMPA products are post-real-time research products (3B42V6 and 3B42V7), which are gauge adjusted and provide coverage from $50^{\circ} \mathrm{N}-50^{\circ} \mathrm{S}$, and real-time (3B42RT). A brief description of the TMPA product versions and changes through time is presented here; refer to [20-25] for additional details.

The TMPA algorithm merges a number of ground-based observations (in the non-real-time products) with two types of satellite-based observations (i.e., microwave [MW] and infrared [IR]). The MW sensors include the Advanced Microwave Scanning Radiometer-Earth Observing System (AMSR-E), Advanced Microwave Sounding Unit-B (AMSU-B), TRMM Microwave Imager (TMI), and the Spectral Sensor Microwave Imager/Sounder (SSMI/S, in 3B42V7 only), which combine to make the 3B40RT product. The IR observations combine the geostationary satellites (Geostationary Operational Environmental Satellite [GOES], METEOSAT, and GMS/MT-SAT). The MW and IR observations constitute the TMPA 3B40RT and 3B41RT products, respectively. Together these products are used to generate the 3B42RT product, which when combined with the Global Precipitation Climatology Center (GPCC), TMI, TRMM Precipitation Radar, and the Climate Assessment and Monitoring System (CAMS, only in the V6 algorithm) produce the post-real-time 3B42V6 and 3B42V7 products [24].

Over the past decade, the TMPA algorithm produced at NASA has undergone three major improvements as a result of algorithm upgrades and the addition of new satellite sensors. The TMPA V5 product (not analyzed in this study) introduced the Advanced Microwave Scanning Radiometer (AMSR-E) and three Advanced Microwave Sounding Unit-B (AMSU-B) sensors into the algorithm in 2005 [24]. The V6 
algorithm was released in 2009 and utilized the climatological calibration algorithm (CCA) to reduce systematic bias. The most recent upgrade in June 2012 (V7 release) made more substantial changes including: (1) inclusion of SSMI/S; (2) the latest release of GPCC; (3) data from the early part of the Microwave Humidity Sounder (MHS); (4) new IR brightness temperature data from the National Climatic Data Center (NCDC) GridSat-B1 from 1998 to 2000; and (5) the use of TRMM Precipitation Radar (PR) products (only in the TRMM combined product as a calibrator). More details on the most recent changes from V6 to V7 are discussed in Huffman et al. [26].

It is known that the precision of satellite products is dependent on a number of factors such as the terrain, precipitation type, and climate [15,27,28]. A number of studies have investigated the uncertainties of satellite precipitation over varying climatic, geographic, and topographic regimes, where it is known to both under- or overestimate actual precipitation [29-36]. Recent investigations have attempted to determine the optimal satellite rainfall product (e.g., [19,24,30]) and break down the errors [37-39], yet limited research has been done in arid environments and specifically the MENA region, due to the paucity of monitoring stations needed for statistical comparison.

Unfortunately, the number of research studies integrating TMPA data into various scientific applications (e.g., water resources, rainfall analysis, climate change, hydrologic modeling, etc.) ([19,40-59]; among others) has far outweighed those studying the accuracy, uncertainty, and validation of TMPA data ([13,18,24,45,60,61]; among others). Even less research has been conducted on the viability of TMPA rainfall products as an adequate substitute for field gauges in data sparse and arid to semi-arid environments $[11,18]$; arguably the area most critically in need of satellite rainfall.

In addition, the transition from the 3B42V6 product to the 3B42V7 occurred in June 2012; however, due to the accidental omission of the AMSU calibration data in the $\mathrm{V} 7$ product an error was produced from June 2012 to November 2012, which resulted in the creation of a reprocessed product in December 2012 (3B42V7a) to account for the minor correction [24,62]. The algorithm developers quickly reprocessed the data and provided the correct version in late January 2013. More details about this update can be found in Huffman and Bolvin [63]. A few months later this product reverted back to the original naming convention (3B42V7). For this paper, the original V7 data released from June 2012 to January 2013 is referred to as $\mathrm{V} 7_{\text {temp }}$ while the corrected version (V7a) will be referred to as $\mathrm{V} 7$ to match the current naming convention. A few studies utilized the original $\mathrm{V} 7_{\text {temp }}$ data [22], as well as investigated the follow-up version V7a without specifying the V7a by name [21]; however, to our knowledge there are no studies that quantify these errors or evaluate their impacts on the published scientific literature.

This manuscript compares in situ rain gauge stations in Northern Morocco, a diverse topographical and climatic region, against multiple TRMM satellite precipitation products (TMPA 3B42 V6, 3B42 V7temp, 3B42 V7, and 3B42 RT-V7) to address the aforementioned shortcomings by: (1) assessing the accuracy of the TMPA products to test whether they are reliable for hydrologic investigations and whether the TMPA algorithm enhancements have significantly improved the performance metrics in the MENA region; (2) evaluating the TMPA products in critical areas (diverse climate, complex terrain); (3) providing data and an assessment of the TMPA products in arid and data-sparse regions (e.g., Middle East \& North Africa); and (4) examining and quantifying the bias during the processing errors from V6 to $\mathrm{V} 7$ that resulted in the temporary product designation of $\mathrm{V} 7 \mathrm{a}$.

The comparison involved a three-fold approach: (1) average annual precipitation values from 125 widespread field gauges in Morocco were compared to the TMPA datasets; (2) gauges were grouped 
into three elevation classes (Low: 0-500 m; Medium: 500-1000 m; and High: $>1000 \mathrm{~m}$ ) and precipitation/climate classes (Arid: 100-300 mm/year; Semi-Arid: 300-500 mm/year; and Humid: $>500 \mathrm{~mm} /$ year) to evaluate the impact of rainfall magnitudes and elevation on satellite-based rainfall products; and (3) statistical analyses (e.g., RMSE, Percent Bias, Nash-Sutcliffe Efficiency, and Pearson Correlation Coefficient) were conducted for each TMPA product in each environment.

This research addresses one of the major difficulties facing hydrologists and demonstrates the opportunities and challenges of using TMPA precipitation in these critical areas and for supplying rainfall data in the data sparse regions of the World. It also quantifies the errors associated with the various TMPA products and releases and provides a platform for enhanced algorithm development in the new Global Precipitation Measurement (GPM) era.

\section{Site Description}

The study area is characterized by a climate that represents a transition between the temperate climate in Europe and the very dry climate of the Saharan desert. The Moroccan climate varies from sub-humid at the Mediterranean coastal zones, to semi-arid in the center, and to arid and hyper-arid in the south. Generally, the precipitation decreases from north to south and from west to east [64]. The spatial and temporal precipitation distributions are affected by the Atlantic Ocean, the Mediterranean Sea, and the Sahara and Atlas Mountains [65]. Several studies demonstrated strong correlations between inter-annual precipitation variability and the North Atlantic Oscillation (NAO), the Atlantic Multi-Decadal Oscillation (AMO), and the El Niño-Southern Oscillation (ENSO) indices [65-68]. Therefore, both local and large-scale factors impact the precipitation that is characterized by a strong irregularity in time and space. This variability is reflected particularly in the amounts of water availability/capita/area; the basins in the NW parts of the country provide $2000 \mathrm{~m}^{3} /$ capita/year, whereas those in the SE yield less than $150 \mathrm{~m}^{3} / \mathrm{capita} /$ year. The general lack of information on the Middle East and North Africa region coupled with the variable climate and complex terrain of Northern Morocco, make it a suitable location for evaluating the performance of the TMPA products.

In this study, we used precipitation data from 125 stations located in the Moulouya basin, Sebou basin, Oum Er Rbia basin, and the Rif watersheds (Figure 1). The Oum Er Rbia basin area is $37,881 \mathrm{~km}^{2}$ and encompasses the longest river of Morocco (i.e., the Oum Er Rbia River) [69]. The Oum Er Rbia annual precipitation is around $340 \mathrm{~mm}$ and elevations in the catchment range from $3986 \mathrm{~m}$ in the High Atlas to $0 \mathrm{~m}$ in the coastal Meseta plain.

The Melouya basin extends over $55,910 \mathrm{~km}^{2}$ with an average annual precipitation of $240 \mathrm{~mm}$. The Moulouya River originates from the High Atlas in the south, the high plateau in the east, the Middle Atlas in the west, and the eastern Rif in the northwest, to reach the eastern Mediterranean coast of Morocco [70]. Elevations in the basin reach a maximum elevation of $3727 \mathrm{~m}$.

The Sebou basin is characterized by a strong rainfall gradient with a mean annual rainfall of $560 \mathrm{~mm}$. The Sebou basin extends over an area of $38,835 \mathrm{~km}^{2}$, with elevations ranging from $0 \mathrm{~m}$ to $3047 \mathrm{~m}$. The basin is one of the most populated regions of Morocco and represents the country's most important agricultural region with more than $19,200 \mathrm{~km}^{2}$ of irrigated land [70].

The Rif Mountains are characterized by steep slopes and demonstrate complex structural and topographic features creating numerous small-sized catchments. Sixty-six watersheds originate in the 
Rif Mountains and drain toward the Mediterranean Sea or the Atlantic Ocean, ranging in size between 20 and $3730 \mathrm{~km}^{2}$. The western Rif catchments receive very high precipitation, exceeding on average $750 \mathrm{~mm} /$ year, while the eastern catchments receive an average of $350 \mathrm{~mm} /$ year.

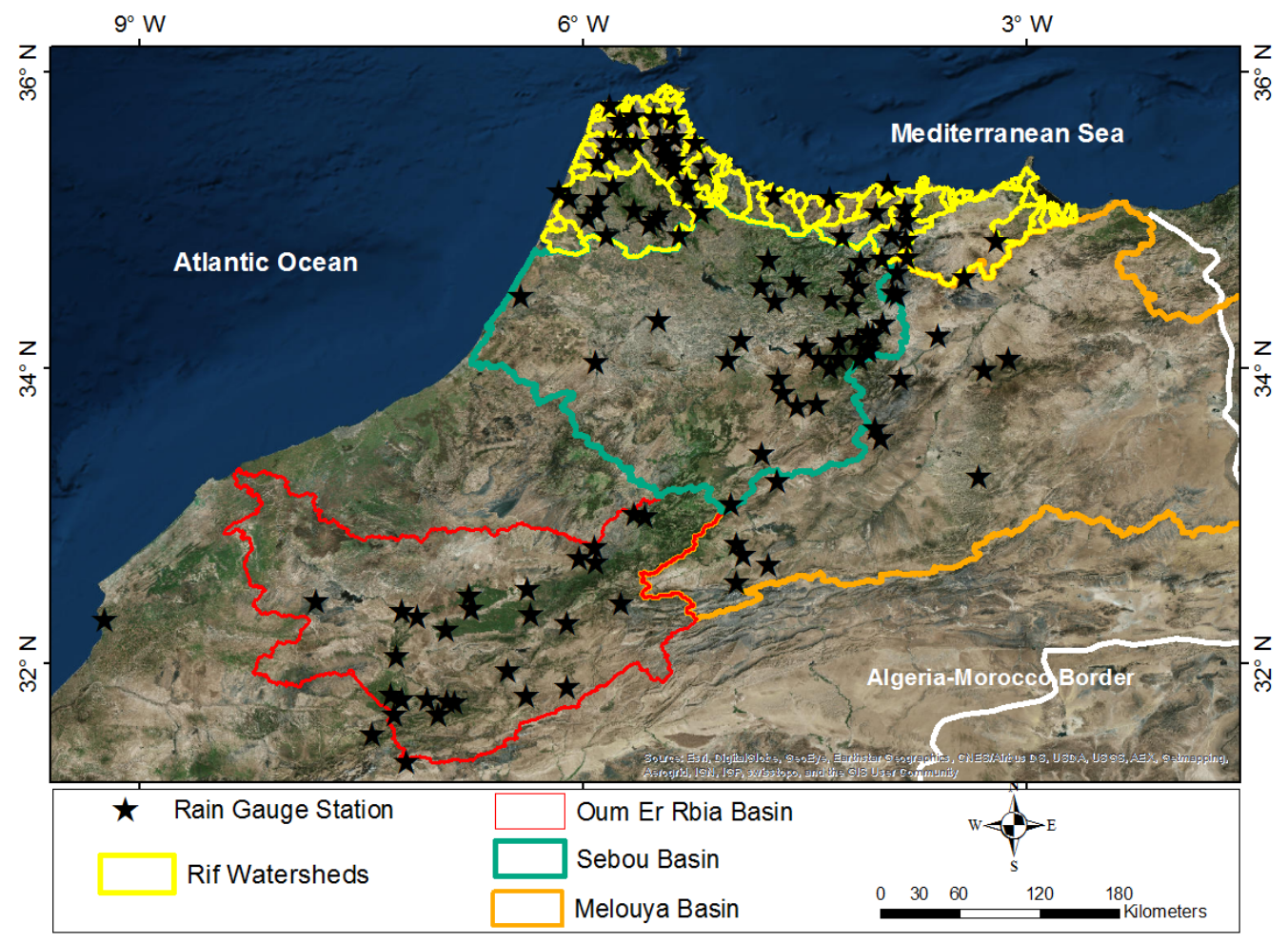

Figure 1. Northern Morocco with locations of $\sim 125$ rain gauges (black stars) covering the period 1930-2012, provided by the Loukous, Oum Er Rbia, Sebou, and Melouya Hydraulic Basin Agencies.

\section{Methodology}

A three-fold approach was conducted to: (1) determine if TRMM satellite precipitation data is capable of accurately characterizing the spatial and temporal variability of rainfall in Northern Morocco; (2) investigate whether the recent TMPA algorithm developments had a positive impact on the statistical correlation with field gauges in Morocco; (3) statistically evaluate the TMPA products in varying rainfall and elevation environments; and (4) quantify the bias in the temporary V7 product ( $\mathrm{V} 7_{\text {temp }}$ ). More specifically, (1) average annual precipitation values from 125 wide-spread field gauges in Morocco were utilized and compared against the merged TMPA daily-derived products (3B42-V6, 3B42-V7temp, 3B42-V7, and 3B42-RT); (2) gauges were grouped into three elevation classes (Low: 0-500 m (64 gauges); Medium: 500-1000 m (32 gauges); High: >1000 m (24 gauges)) and precipitation/climate classes (Arid: 100-300 mm/year (29 gauges); Semi-Arid: 300-500 mm/year (49 gauges); Humid: >500 mm/year (52 gauges)) to evaluate the impact of rainfall magnitudes and elevation on satellite-based rainfall products (Figure 2); and (3) statistical correlations (e.g., RMSE, Percent Bias, Nash-Sutcliffe efficiency coefficient, and Pearson Correlation Coefficient) were determined for each TMPA product in each environment. 


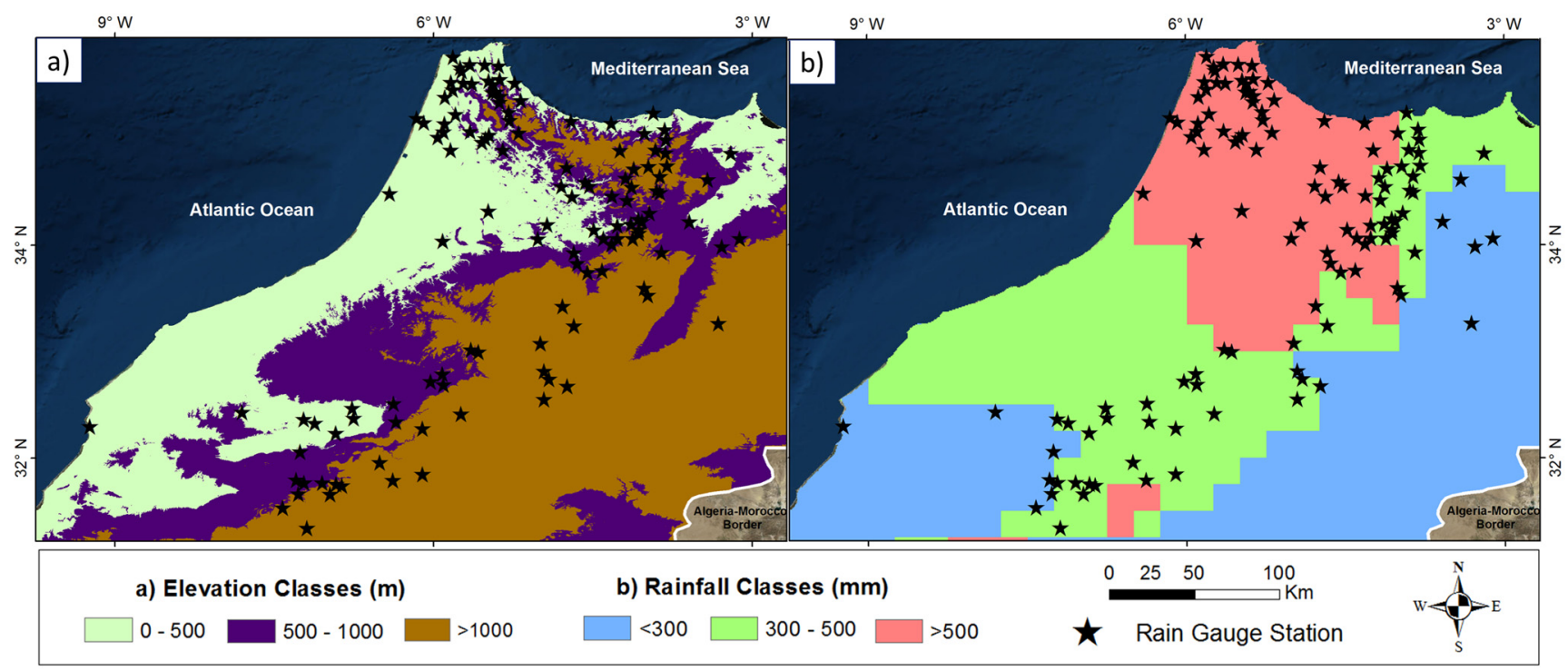

Figure 2. (a) Elevation classes of Northern Morocco; (b) Average annual precipitation (climate) classes in Northern Morocco.

\section{Data Acquisition and Processing}

\section{Rain Gauge and Satellite Data}

Data from 179 rain gauges over the Oum Er Rbia, Moulouya, Rif, and Sebou Watersheds located in Northern Morocco was acquired from local water agencies (e.g., Oum Er Rbia Hydraulic Basin Agency, Moulouya Hydraulic Basin Agency, Loukkos Hydraulic Basin Agency, and Sebou Hydraulic Basin Agency). The precipitation data collection, storage, analyses, and correction were completed according to the World Meteorological Organization standard code WMO-N 168 [71]. The rain gauge data (179 in total) ranges from 1978 to 2012, though the analysis was restricted to the 125 stations that had temporal coverage that overlaps the existence of TRMM (1998-Present) (Figure 1). Annual precipitation totals were then computed and checked for accuracy from the 125 stations. The gauge data were divided into three climatic classes (Arid: 100-300 mm/year; Semi-Arid: 300-500 mm/year; Humid: >500 mm/year). The classification scheme is based on total annual rainfall [72] and was adapted to Morocco by considering the UNEP's distribution of arid zones [73,74]. The annual precipitation amounts were computed using the rain gauges and grouped into the classification zones using ArcGIS. Similarly, the gauge data was divided into three elevation classes (Low: 0-500 m; Medium: 500-1000 m; High: >1000 m), using a quantile classification for the study area.

Four different TMPA precipitation product versions (3B42V6, 3B42V7temp, 3B42V7, and 3B42RT) were acquired from NASA Mirador for the period 1998-2012, with the exception of 3B42V6, which was replaced on 30 June 2011, and the 3B42RT, which was evaluated starting in 2001 after its first full year. All files were processed and daily, monthly, and annual values were computed by simple summation of the individual files using ENVI and ArcGIS. The 3B42RT is the TMPA near-real-time product that is not gauge corrected and thus should show the most variation in correlation. 
Analysis and Comparison of Rainfall Products

The comparison of ground-based observations (e.g., rain gauges) to satellite products is difficult given the different spatial and temporal uncertainties. The intent of this research was to demonstrate the lower threshold of accuracy and therefore gauges (point measurements) were compared directly to gridded satellite products $(0.25 \times 0.25$ degree cells $)$ regardless of position within the grid point. A comprehensive set of statistical measures (Pearson Correlation Coefficient (PCC), Nash-Sutcliffe Efficiency Coefficient (NSE), Root Mean Square Error (RMSE), and Percent Bias (PBIAS)) were performed on an annual time scale to evaluate the performance of the different TMPA products.

The Nash-Sutcliffe efficiency (NSE) compares the relative magnitude of residual difference to the measured data difference [75]. The NSE value is based on the dispersion of variants around the line of equal values and indicates how well the plot of observed versus estimated data fits the 1:1 line. NSE values can range from $-\infty$ (poor fit) to 1.0 (perfect fit). A more detailed performance rating breakdown for the NSE values can be found elsewhere [76]. The expression for NSE is shown in Equation (1):

$$
N S E=1-\left[\frac{\sum_{i=1}^{n}\left(Y_{i}^{o b s}-Y_{i}^{s i m}\right)^{2}}{\sum_{i=1}^{n}\left(Y_{i}^{o b s}-\bar{Y}^{o b s}\right)^{2}}\right]
$$

where $Y_{i}^{o b s}$ is the gauge-based precipitation measurement, the $Y_{i}^{\text {sim }}$ is the satellite-based precipitation measurement, and $\bar{Y}^{o b s}$ is the mean of the gauge-based precipitation measures.

The Pearson Correlation Coefficient (PCC) is the average product of the deviation of two variables from their respective means divided by the product of the standard deviations of those variables. The equation for the correlation coefficient is:

$$
P C C=\frac{\sum_{i=1}^{n}\left(Y_{i}^{o b s}-\bar{Y}^{o b s}\right)\left(Y_{i}^{s i m}-\bar{Y}^{s i m}\right)}{\sqrt{\sum_{i=1}^{n}\left(Y_{i}^{o b s}-\bar{Y}^{o b s}\right)^{2}} \sqrt{\sum_{i=1}^{n}\left(Y_{i}^{s i m}-\bar{Y} s i m\right)^{2}}}
$$

where $Y_{i}^{o b s}$ is the gauge-based precipitation measurement, the $Y_{i}^{\text {sim }}$ is the satellite-based precipitation measurement, $\bar{Y}^{o b s}$ is the mean of the gauge-based precipitation measurements, and $\bar{Y} \operatorname{sim}$ is the mean of the satellite-based measurements.

The root-mean-square error (RMSE) is a measure of the differences between predicted and observed values. The RMSE serves to combine the magnitudes of the errors in predictions for various times into a single measure of predictive power. The RMSE is calculated with Equation (3):

$$
R M S E=\sqrt{\frac{\sum_{i=1}^{n}\left(Y_{i}^{o b s}-Y_{i}^{s i m}\right)}{n}}
$$

where $Y_{i}^{o b s}$ is the gauge-based precipitation measurement, the $Y_{i}^{s i m}$ is the satellite-based precipitation measurement, and $n$ is the total number of pair (gauge, satellite) measurements.

We normalized the RMSE to conduct an objective comparison between the various classes. The normalized root-mean-square error (NRMSE) is calculated with Equation (4):

$$
N R M S E=\frac{R M S E}{Y_{\max }-Y_{\min }}
$$

where $Y_{\max }$ and $Y_{\min }$ are the maximum and minimum precipitation amounts respectively, over the evaluated class. 
Percent bias (PBIAS) measures the average tendency of the simulated data to be overestimated or underestimated versus observed data measurements [76,77]. PBIAS is calculated with Equation (5):

$$
P B I A S=\left[\frac{\sum_{i=1}^{n}\left(Y_{i}^{\text {sim }}-Y_{i}^{o b s}\right) \times(100)}{\sum_{i=1}^{n}\left(Y_{i}^{o b s}\right)}\right]
$$

where $Y_{i}^{o b s}$ is the gauge-based precipitation measurement and $Y_{i}^{\text {sim }}$ is the satellite-based precipitation measurement.

Accurate comparisons are indicated by low-magnitude PBIAS values (0.0). Underestimation and overestimation biases are indicated by negative and positive PBIAS values, respectfully.

\section{Results and Discussion}

Using the aforementioned statistical tests we examined the correlation, bias, spatial, and temporal variations of the four products (V6, V7 temp, V7, RT) overall and in the previously specified pre-defined classes (rainfall, elevation). These results are shown in the following sections.

\subsection{TMPA Statistical Correlations}

\subsubsection{Unclassified (Entire) Data}

Findings indicate the best overall correlation between gauge-based and satellite-based rainfall measurements is the TMPA V7 (PCC: 0.875; NSE: 0.729; NRMSE: 0.072) product, followed by TMPA V7 temp (PCC: 0.840; NSE: 0.706; NRMSE: 0.072), then TMPA V6 (PCC: 0.805; NSE: 0.566; NRMSE: 0.088), and finally TRMM RT (PCC: 0.715; NSE: 0.462; NRMSE: 0.104) (Table 1). Only 8 out of 112 statistical evaluations, regardless of the classification scheme, deviated from this order (V7 or $\mathrm{V}_{\text {temp }}>\mathrm{V} 6>\mathrm{RT}$ ) (Table 1: highlighted in yellow). This trend is also seen in the scatter plots of the three different products, where the values better fit the trend line (Figure 3).

TMPA tends to either over- or under-estimate precipitation depending on the various product version, climate, and elevation as seen in the percent bias calculations (PBIAS) (Table 1). These results show an overall underestimation in nearly all of the TMPA products (V6: $-17 \%$; V7 temp: $0.4 \%$; V7: $-3.8 \%$; and RT: $-13 \%$ ) (Table 1: "Unclassified"). Again, the TMPA V7 product exhibits a limited bias in Northern Morocco.

\subsubsection{Elevation-Based Classification}

The elevation-based classification results showed a decrease in correlation with an increase in elevation (Table 1; Figure 4). The average PCC for the low, mid, and high elevations is $0.84,0.80$, and 0.45 , respectively. The average NSE and NRMSE results echoed the PCC results where the best correlations were in the low elevation areas (Low-NSE: 0.66, NRMSE: 0.08; Mid-NSE: 0.51, NRMSE: 0.10; and High-NSE: 0.37, NRMSE: 0.14). These results suggest that TRMM sensors can accurately estimate precipitation events in elevations less than $1000 \mathrm{~m}$ but struggle with higher elevations, as was the case in similar high-altitude studies [21,24]. Areas with high snow content are problematic due to the sensitivity to the surface emissivity in passive microwave sensors (e.g., TMI, SSM/I, SSMIS, AMSU, AMRS-E), which produces signals similar to those of precipitation $[21,78,79]$. 

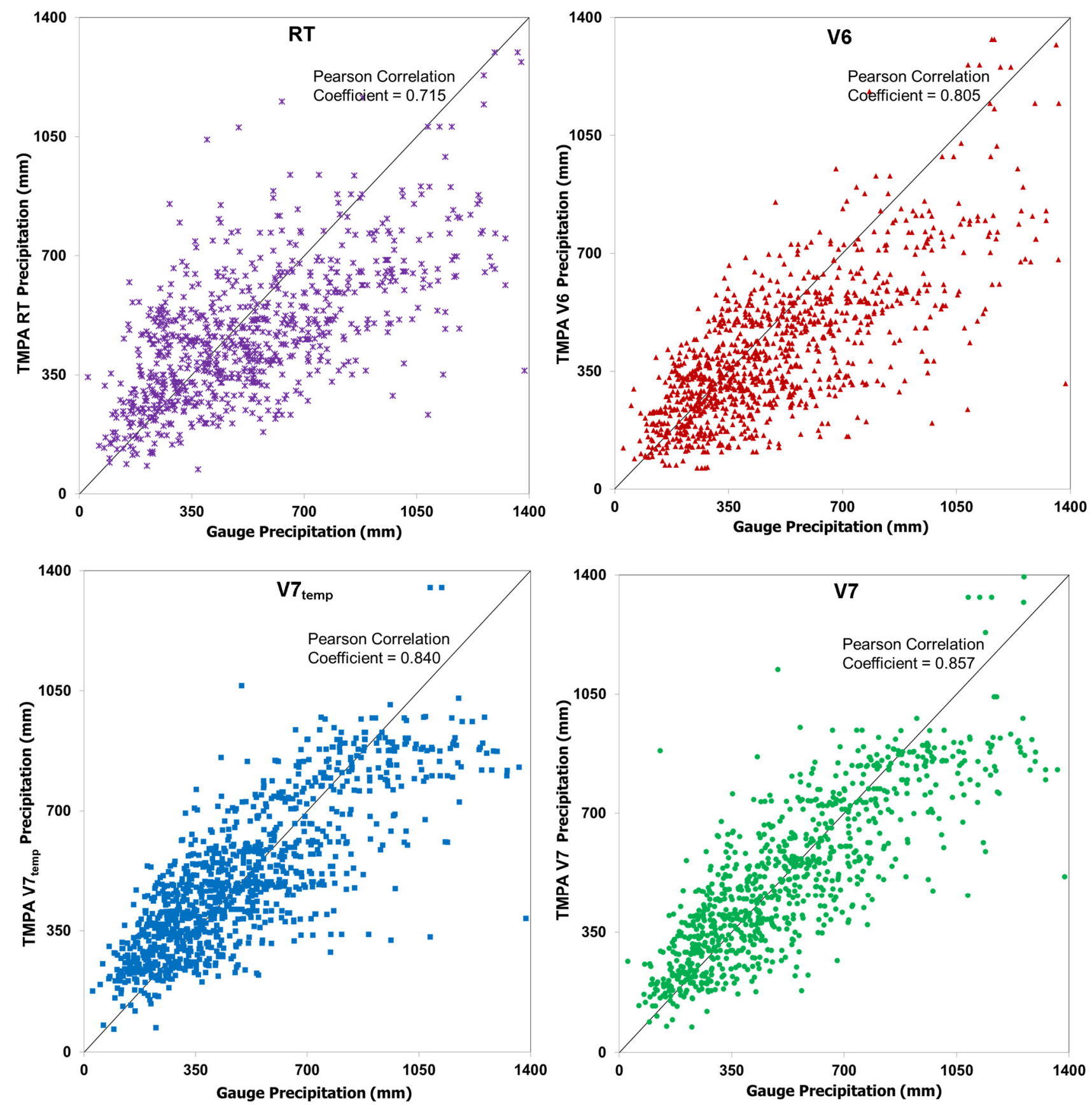

Figure 3. Scatter plots of the various TMPA products (RT: purple crosses, V6: red triangles, $\mathrm{V} 7_{\text {temp: }}$ blue squares; V7; green squares) versus gauge precipitation $(\mathrm{mm})$ data for the entire unclassified network. 

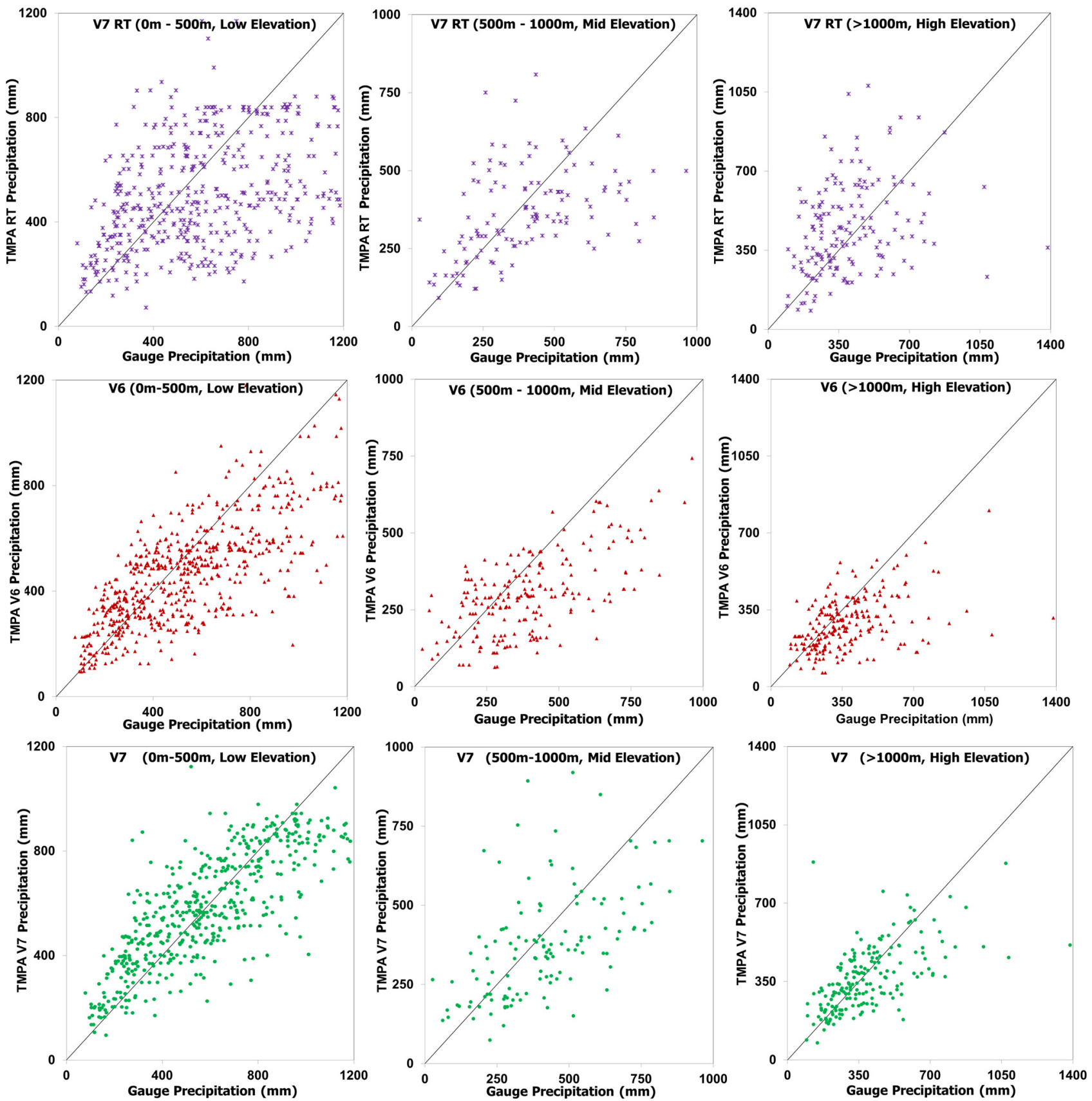

Figure 4. Scatter plots of the various TMPA products (RT: purple crosses, V6: red triangles, V7; green squares) versus gauge precipitation $(\mathrm{mm})$ data for the elevation-based classification.

In addition, both a climate and elevation bias exists. The elevation-based classification showed there is no consistent positive or negative precipitation bias for the four products; however, the general trend is an underestimation of precipitation in the varying elevation classes. The largest average bias (-18\%) is found in the mid-elevations (e.g., 500-1000 m), as compared to the low $(-9 \%)$ and high $(-12 \%)$ elevation classes. In particular, the TMPA RT product showed an overestimation of precipitation that was not seen in any other product. The lowest variance in bias was seen in the low elevation classes, supporting the literature documenting the difficulty of TRMM in complex topography $[21,24]$. 
Table 1. Statistical summary of the TMPA products analyzed in this study.

\begin{tabular}{|c|c|c|c|c|c|}
\hline & TMPA Product/Classification & NSE & PCC & NRMSE & PBIAS \\
\hline \multirow{12}{*}{ 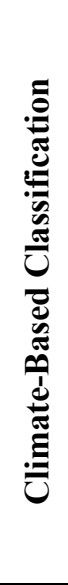 } & TMPA 6: Arid & $-0.3107 *$ & 0.5460 & 0.1561 & $14.8306 *$ \\
\hline & TMPA $7_{\text {temp: }}$ Arid & -1.4170 & 0.6810 & 0.1826 & 46.9815 \\
\hline & TMPA 7: Arid & -0.5129 & 0.6970 & 0.1494 & 28.4758 \\
\hline & TMPA RT: Arid & -1.6529 & $0.5620 *$ & 0.2066 & 38.6636 \\
\hline & TMPA 6: Semi_Arid & -0.0829 & 0.4940 & $0.1448 *$ & -12.1629 \\
\hline & TMPA 7 7emp: Semi_Arid & 0.0052 & 0.5490 & 0.1486 & 10.5142 \\
\hline & TMPA 7: Semi_Arid & -0.0248 & 0.5480 & 0.1512 & 5.9406 \\
\hline & TMPA RT: Semi_Arid & -0.4581 & 0.3050 & 0.1806 & $4.6038 *$ \\
\hline & TMPA 6: Sub_Humid & 0.2747 & 0.7550 & 0.1171 & -23.4304 \\
\hline & TMPA $7_{\text {temp }}$ :Sub_Humid & 0.5764 & 0.7900 & 0.0921 & -8.4049 \\
\hline & TMPA 7: Sub_Humid & 0.6006 & 0.8160 & 0.0902 & -10.4856 \\
\hline & TMPA RT: Sub_Humid & 0.1829 & 0.7280 & 0.1331 & -24.9839 \\
\hline \multirow{12}{*}{ 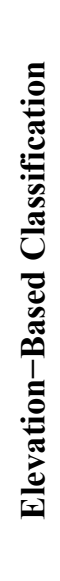 } & TMPA 6: Low_Elev & 0.6092 & 0.8180 & 0.0910 & -14.0130 \\
\hline & TMPA $7_{\text {temp }}$ : Low_Elev & 0.7385 & 0.8620 & 0.0734 & 3.4305 \\
\hline & TMPA 7: Low_Elev & 0.7677 & 0.8790 & 0.0710 & -0.3870 \\
\hline & TMPA RT: Low_Elev & 0.5292 & 0.8020 & 0.1032 & -17.7135 \\
\hline & TMPA 6: Mid_Elev & 0.4465 & 0.8100 & 0.0994 & -27.0902 \\
\hline & TMPA 7 temp: Mid_Elev & 0.5874 & 0.8220 & 0.0863 & -10.0360 \\
\hline & TMPA 7: Mid_Elev & 0.5968 & 0.8430 & 0.0909 & -16.5857 \\
\hline & TMPA RT: Mid_Elev & 0.4095 & 0.7180 & 0.1127 & $-17.7744 *$ \\
\hline & TMPA 6: High_Elev & -0.0434 & 0.4420 & 0.1459 & -22.8784 \\
\hline & TMPA $7_{\text {temp }}:$ High_Elev & 0.3306 & 0.5850 & 0.1175 & -1.9493 \\
\hline & TMPA 7: High_Elev & 0.3229 & 0.5980 & 0.1251 & -7.0437 \\
\hline & TMPA RT: High Elev & -0.7576 & 0.2250 & 0.1742 & $14.2622 *$ \\
\hline \multirow{4}{*}{ 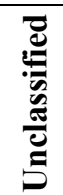 } & TMPA 6: All & 0.5664 & 0.8050 & 0.0878 & -17.5836 \\
\hline & TMPA $7_{\text {temp }}$ : All & 0.7057 & 0.8400 & 0.0720 & 0.4033 \\
\hline & TMPA 7: All & 0.7295 & 0.8570 & 0.0720 & -3.7902 \\
\hline & TMPA RT: All & 0.4624 & 0.7150 & 0.1038 & $-13.2630 *$ \\
\hline
\end{tabular}

* Data that do not follow the expected trend (i.e., V7 (or V7 temp) are better than V6, and V6 is better than RT).

\subsubsection{Climate-Based Classification}

The climate-based classification confirms the deficiencies in estimating low precipitation events often found in arid (Average PCC: 0.62) and semi-arid (Average PCC: 0.47) areas, with the TMPA V7 data outperforming the other datasets (Figure 5). The sub-humid areas had the highest correlation (Average PCC: 0.77 ). The results of the average NSE and NRMSE for the arid (NSE: -0.96 ; NRMSE: 0.17), semi-arid (NSE: -0.14; NRMSE: 0.16), and sub-humid (NSE: 0.41; NRMSE: 0.11) were generally consistent with the PCC results, as also seen in the elevation-based classification. The sub-humid classification resulted in the only positive NSE correlation as well as the highest PCC and smallest NRMSE. This is attributed to the fact that TRMM was designed to estimate precipitation in wet and humid tropical areas.

TMPA overestimates precipitation in arid environments (average PBIAS: 30\%) and underestimates it in sub-humid climates (average PBIAS: $-16 \%$ ), whereas the semi-arid climates exhibited little bias (average PBIAS: $-3 \%$ ). This is consistent with other findings in these environments $[21,24]$. 

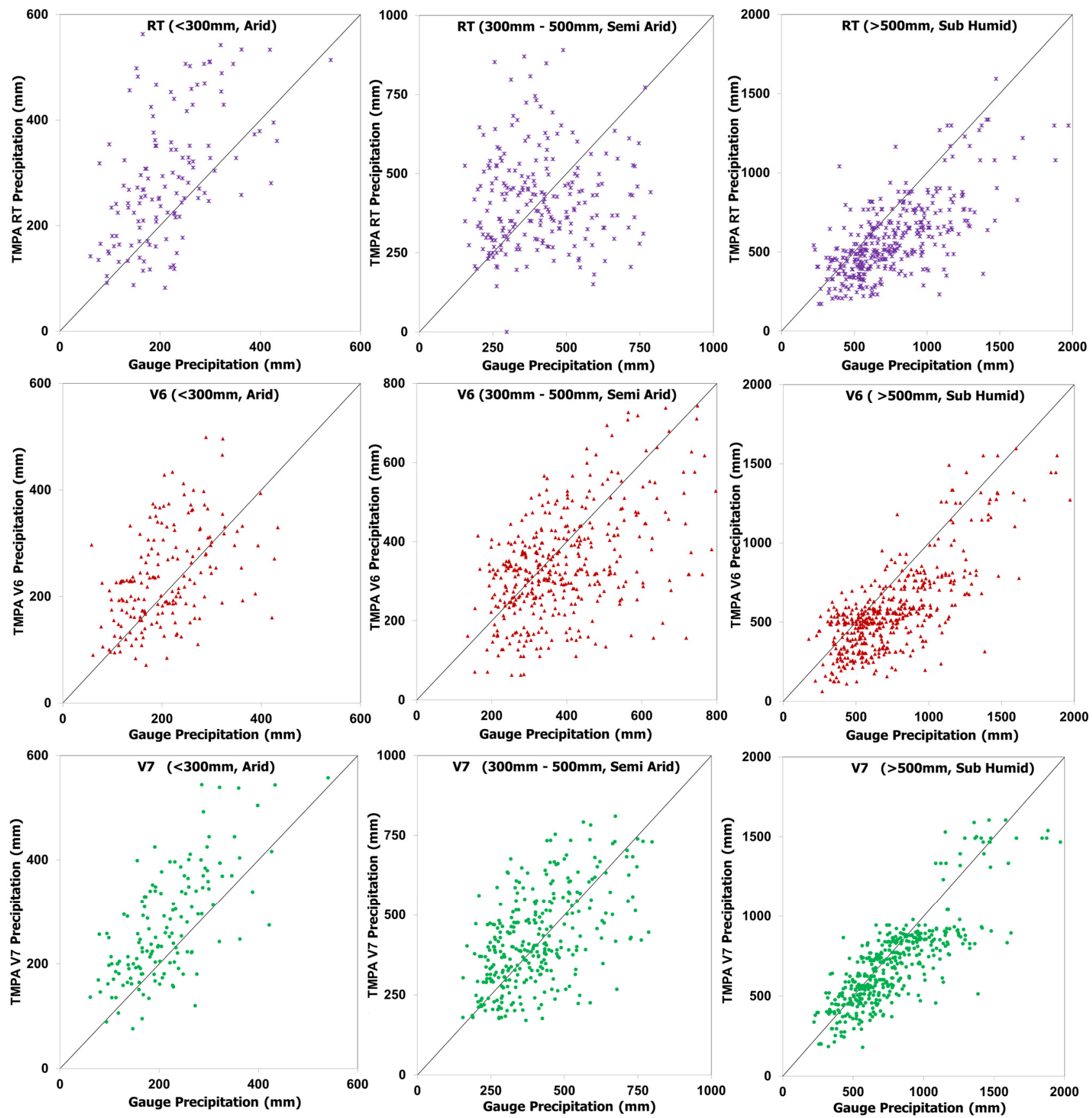

Figure 5. Scatter plots of the various TMPA products (RT: purple crosses, V6: red triangles, $\mathrm{V} 7$; green squares) versus gauge precipitation $(\mathrm{mm})$ data for the climate-based classification.

\subsection{Temporal Variations of TMPA}

Inspection of Figure 6 shows temporal variations in precipitation between the gauge data and the various TMPA products, and validates the superiority of the TMPA V7 (green line) product as compared to the other products (V6 and RT). Overall, the best performing TMPA product order is the V7 (green line), V6 (Red line), then RT (purple line) (Figure 6). The highest correlation coefficients overall are seen in "wet" years (2003, 2008-2010); while the lowest correlations are seen in "dry" years (e.g., 2001, 2005, 2011). 


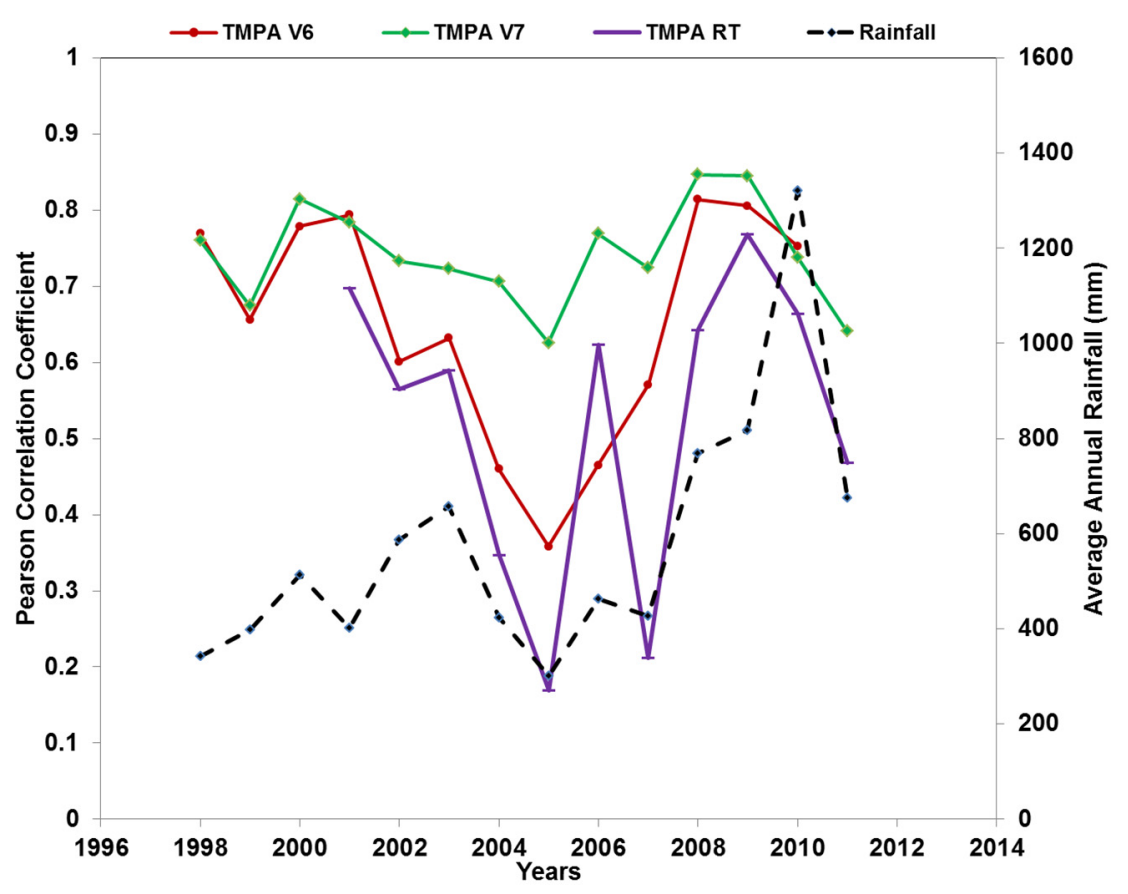

Figure 6. Time series of the overall Pearson Correlation Coefficients for the TMPA products (Primary Axis-RT: purple line; V6: blue line; V7: green line) and rainfall data (Secondary Axis-dashed line).

\subsection{Spatial Variations of TMPA}

An evaluation of the correlation coefficient spatially throughout the study area confirms the previous findings in Section 4.2 (Figure 7). The RT product performs the worst (Figure 7a: blue areas) while the TMPA V7 has the best correlation with rain gauges (Figure 7d: red areas). Figure 7 also validates the TMPA algorithm development as the amount of least correlated areas (blue areas) decreases from V6 through the most recent product, TMPA 7. The spatial map of correlation coefficients also highlights the successful (i.e., sub-humid) and problematic areas (i.e., mountains).

Zone 1 is characterized by a high correlation for each version including TMPA RT, which performs the worst (Figure 7). This zone is characterized by high rainfall (Figure 2b), due to a combined influence of the Atlantic Ocean and the Mediterranean Sea, leading to a sub-humid climate in this zone. Zone 1 is also characterized by various elevation ranges (Figure 2), which suggests that rainfall is the biggest contributing factor to the performance of the satellite products. Zone 2 is characterized by low correlation in all versions including TMPA V7, which outperformed the other product versions (Figure 7). This is possibly due to the limited number of gauges in Zone 2 ( 7 gauges) as compared to Zone 1 (35 gauges). This area is characterized by high elevations (i.e., the Atlas Mountains) with high snow content and low rainfall (Figure 2). All of these are known problematic environments for TMPA products and thus not surprisingly this area was a low correlation zone for all of the products studied in this manuscript. The rest of the study area picture elements are characterized by various combinations of topographical and climatic conditions between these two end members (i.e., Zone 1 and Zone 2), thus leading to correlations ranging between the two extremes in all TMPA versions. 


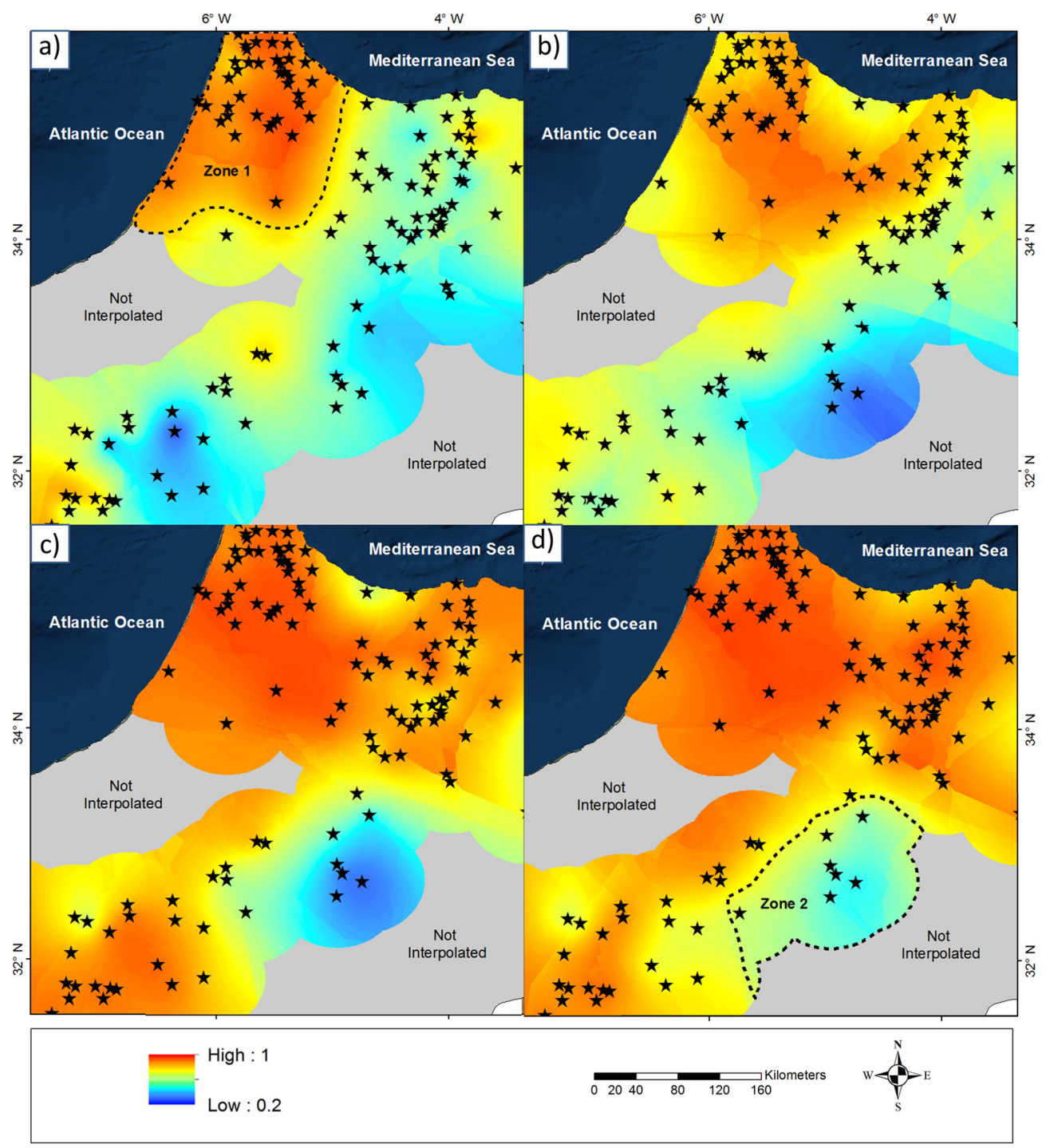

Figure 7. Interpolated Pearson Correlation Coefficients of the TMPA products in the study area. Interpolations were restricted to $50 \mathrm{~km}$ from a gauge location. (a) RT; (b) V6; (c) V7 temp; (d) V7. Areas in red represent high correlation, and blue areas represent low correlation. Zone 1 corresponds to high correlation areas for all four products while Zone 2 represents an area of all low correlations.

\section{Conclusions and Summary}

We evaluated the performance of various rainfall satellite products (TMPA 3B42 V6, 3B42 V7 temp, 3B42 V7, and 3B42 RT) using 125 rain gauges in Morocco. This study supports the conclusion that the bias in the TMPA precipitation products depends on the rainfall pattern and elevation $[21,24,80]$. Overall, of the TMPA products studied here, the findings of the statistical analysis of the various regions can be interpreted as follows:

(1) Generally, the newer and refined satellite products have achieved their intended purpose and outperform previous versions. The TMPA research products (3B42 V6 and V7) performed better than the real-time product (3B42 RT). The PCC (V6: 0.81; V7: 0.86), NSE (V6: 0.57; V7: 0.73), NRMSE (V6: 0.08; V7: 0.07), and PBIAS (V6: -17\%; V7: -4\%) statistics of the research products outperformed the real-time product (RT-PCC: 0.72 ; NSE: 0.46; NRMSE: 0.10; 
PBIAS: $-13 \%$ ). This was also true regardless of the classification scheme as 104 out of 112 statistical analyses demonstrated the V7 products performed better than V6, and V6 outperformed the RT product. It should be noted that the RT version offers near-real-time products, which is an advantage compared to the research products. This validates the efforts and purpose of the recent algorithm developments and is consistent with similar findings [21,24].

(2) A relatively low correlation was found between satellite observations and gauge data in areas receiving less than $500 \mathrm{~mm} / \mathrm{yr}$, consistent with recent investigations in other locations [21]. The analyses demonstrate that V7 still has an overestimation bias in arid environments (trend line slope: 1.13), and an underestimation bias in both semi-arid environments (trend line slope: 0.60) and sub-humid environments (trend line slope: 0.68). Results suggest that all versions are consistently better correlated with field gauges in sub-humid environments (PCCs-V6: 0.755; V7 temp: 0.790; V7: 0.816; and RT: 0.728) than in semi-arid environments (PCCs—V6: 0.494; V7 temp: 0.549, V7: 0.548; and RT: 0.305) or arid environments (PCCs - V6: 0.546; V7 temp: 0.681; V7: 0.697; and RT: 0.562). Moreover, the arid environments had negative NS values for every product, suggesting that the mean observed value is a better predictor of observed rainfall than TMPA. Though this is the first TMPA comparison study in North Africa, the difficulty in estimating precipitation in arid environments was still apparent and is attributed to the land surface properties of the desert, which impact the upwelling microwave radiation [81]. These issues should be reduced in the GPM era because of the higher frequency channels on the GPM Microwave Imager (GMI) and Dual-Frequency Precipitation (DPR) sensors.

(3) The elevation of the area contributes to the accuracy and reliability of the satellite observations. The lowest elevation resulted in the highest degree of correlation between all of the products with an average PCC of 0.84 as compared to the mid-elevation (PCC: 0.80 ) and high-elevation (PCC: $0.45)$. This study showed a potential altitude threshold exists as the correlation is drastically reduced in the highest elevations $(>1000 \mathrm{~m})$, though these were also the low rainfall or snow accumulation areas. In general, TMPA products underestimated the precipitation throughout the different elevation regimes with the mid-elevations showing the worst bias (PBIAS-Low: $-9 \%$; Mid: $-20 \%$; and High: $-12 \%$ ), though the RT product exhibited an overestimation bias in the high-elevation classification. Similar studies have outlined the low performance of TMPA products in high-altitude environments and identified the possible cause to be the bright band, ground clutter, or the attenuation of the PR reflectivity [21,78,79].

(4) The temporary processing error (V7 temp) from June 2012 to January 2013 resulted in a percent bias of $\sim 4 \%$ overall between the $\mathrm{V} 7$ and $\mathrm{V} 7$ temp data, though a much larger error (PBIAS: $18 \%$ ) was seen in arid environments. This is consistent with NASA's claim of a $5 \%-8 \%$ error, though it underscores the importance of researchers publishing during that time being cautious about the results they found if they were for low-rainfall environments.

This study demonstrates the accuracy of TMPA precipitation products and highlights the opportunities and challenges of their use in data-scarce regions of the world. The results show the potential for using publicly available remote sensing datasets in lieu of field gauges for data-sparse and inaccessible regions. This study also highlights and could potentially guide the algorithm development of the Global Precipitation Mission (GPM) satellite launched in 2014. Moreover, training satellite-retrieved precipitation 
algorithms on data from Morocco or other similar data scarce regions will lead to more accurate estimations across the MENA region.

\section{Acknowledgments}

The authors would like to thank The University of Georgia Provost Fund for its financial support of the project. The data used in this effort were acquired as part of the activities of NASA's Science Mission Directorate, and are archived and distributed by the Goddard Earth Sciences (GES) Data and Information Services Center (DISC). We would also like to thank the four water basin agencies (L'agence du Basin Hydraulique de la Melouya, L'Agence du Bassin Hydraulique du Sebou, L'Agence du Bassin Hydraulique de l'Oum Er Rbia, and L'Agence du Bassin Hydraulique du Loukkous) for providing the precipitation gauge data. The authors would also like to thank the four anonymous reviewers for their timely and thorough review.

\section{Author Contributions}

Adam Milewski is the principal author of this manuscript and was responsible for the design, processing, interpretation, and writing of the manuscript. Racha Elkadiri made significant contributions to the design, processing, interpretation, writing, and review of the manuscript. Michael C. Durham helped with the design, interpretation, and review of the manuscript.

\section{Conflicts of Interest}

The authors declare no conflict of interest.

\section{References}

1. Brunner, P.; Hendricks Franssen, H.J.; Kgotlhang, L.; Bauer-Gottwein, P.; Kinzelbach, W. How can remote sensing contribute in groundwater modeling? Hydrogeol. J. 2007, 15, 5-18.

2. Di Paola, F.; Ricciardelli, E.; Cimini, D.; Romano, F.; Viggiano, M.; Cuomo, V. Analysis of catania flash flood case study by using combined microwave and infrared technique. J. Hydrometeorol. 2014, 15, 1989-1998.

3. Mugnai, A.; Casella, D.; Cattani, E.; Dietrich, S.; Laviola, S.; Levizzani, V.; Panegrossi, G.; Petracca, M.; Sanò, P.; Paola, F.D. Precipitation products from the hydrology SAF. Nat. Hazards Earth Syst. Sci. 2013, 13, 1959-1981.

4. Puca, S.; Porcu, F.; Rinollo, A.; Vulpiani, G.; Baguis, P.; Balabanova, S.; Campione, E.; Ertürk, A.; Gabellani, S.; Iwanski, R.; et al. The validation service of the hydrological SAF geostationary and polar satellite precipitation products. Nat. Hazards Earth Syst. Sci. 2014, 14, 871-889.

5. Ricciardelli, E.; Cimini, D.; di Paola, F.; Romano, F.; Viggiano, M. A statistical approach for rain intensity differentiation using Meteosat Second Generation-Spinning Enhanced Visible and InfraRed Imager observations. Hydrol. Earth Syst. Sci. 2014, 18, 2559-2576.

6. Silliman, S. Development of Reliable Hydrologic Data Sets in Difficult Environments: Case Studies from Benin, West Africa; Darcy Lecturer, NGWA: Baltimore, MA, USA, 2011. 
7. Sophocleous, M. Global and regional water availability and demand: Prospects for the future. Nat. Resourc. Res. 2004, 13, 61-75.

8. Vörösmarty, C.J. Global water assessment and potential contributions from earth systems science. Aquat. Sci. 2002, 64, 328-351.

9. Casella, D.; Panegrossi, G.; Sano, P.; Dietrich, S.; Mugnai, A.; Smith, E.A.; Tripoli, G.J.; Formenton, M.; di Paola, F.; Leung, W.-Y. Transitioning from CRD to CDRD in Bayesian retrieval of rainfall from satellite passive microwave measurements: Part 2. Overcoming database profile selection ambiguity by consideration of meteorological control on microphysics. IEEE Trans. Geosci. Remote Sens. 2013, 51, 4650-4671.

10. Hong, Y.; Adler, R.F.; Hossain, F.; Curtis, S.; Huffman, G.J. A first approach to global runoff simulation using satellite rainfall estimation. Water Resour. Res. 2007, 43, doi:10.1029/2006WR005739.

11. Milewski, A.; Sultan, M.; Yan, E.; Becker, R.; Abdeldayem, A.; Soliman, F.; Gelil, K.A. A remote sensing solution for estimating runoff and recharge in arid environments. J. Hydrol. 2009, 373, 1-14.

12. Mugnai, A.; Smith, E.; Tripoli, G.; Bizzarri, B.; Casella, D.; Dietrich, S.; di Paola, F.; Panegrossi, G.; Sanò, P. CDRD and PNPR satellite passive microwave precipitation retrieval algorithms: Eurotrmm/Eurainsat origins and H-SAF operations. Nat. Hazards Earth Syst. Sci. 2013, 13, 887-912.

13. Sahoo, A.K.; Sheffield, J.; Pan, M.; Wood, E.F. Evaluation of the tropical rainfall measuring mission multi-satellite precipitation analysis (TMPA) for assessment of large-scale meteorological drought. Remote Sens. Environ. 2015, 159, 181-193.

14. Sanò, P.; Panegrossi, G.; Casella, D.; Di Paola, F.; Milani, L.; Mugnai, A.; Petracca, M.; Dietrich, S. The passive microwave neural network precipitation retrieval (PNPR) algorithm for AMSU/MHS observations: Description and application to European case studies. Atmos. Meas. Tech. Discuss. 2014, 7, 9351-9411.

15. Seyyedi, H.; Anagnostou, E.; Beighley, E.; McCollum, J. Satellite-driven downscaling of global reanalysis precipitation products for hydrological applications. Hydrol. Earth Syst. Sci. 2014, 18, 5077-5091.

16. Ghajarnia, N.; Liaghat, A.; Daneshkar Arasteh, P. Comparison and evaluation of high resolution precipitation Estimation products in Urmia Basin, Iran. Atmos. Res. 2015, 158-159, 50-65.

17. Lo Conti, F.; Hsu, K.-L.; Noto, L.V.; Sorooshian, S. Evaluation and comparison of satellite precipitation estimates with reference to a local area in the Mediterranean Sea. Atmos. Res. 2014, 138, 189-204.

18. Moazami, S.; Golian, S.; Kavianpour, M.R.; Hong, Y. Comparison of persiann and V7 TRMM multi-satellite precipitation analysis (TMPA) products with rain gauge data over Iran. Int. J. Remote Sens. 2013, 34, 8156-8171.

19. Zeng, H.; Li, L.; Li, J. The evaluation of trmm multisatellite precipitation analysis (TMPA) in drought monitoring in the Lancang River Basin. J. Geogr. Sci. 2012, 22, 273-282.

20. Huffman, G.J.; Bolvin, D.T.; Nelkin, E.J.; Wolff, D.B.; Adler, R.F.; Gu, G.; Hong, Y.; Bowman, K.P.; Stocker, E.F. The TRMM multisatellite precipitation analysis (TMPA): Quasi-global, multiyear, combined-sensor precipitation estimates at fine scales. J. Hydrometeorol. 2007, 8, 38-55.

21. Chen, S.; Hong, Y.; Cao, Q.; Gourley, J.J.; Kirstetter, P.E.; Yong, B.; Tian, Y.; Zhang, Z.; Shen, Y.; $\mathrm{Hu}, \mathrm{J}$. Similarity and difference of the two successive V6 and V7 TRMM multisatellite precipitation analysis performance over China. J. Geophys. Res. 2013, 118, 13060-13074. 
22. Chen, S.; Hong, Y.; Gourley, J.J.; Huffman, G.J.; Tian, Y.; Cao, Q.; Yong, B.; Kirstetter, P.E.; Hu, J.; Hardy, J. Evaluation of the successive V6 and V7 TRMM multisatellite precipitation analysis over the continental United States. Water Resour. Res. 2013, 49, 8174-8186.

23. Huffman, G.; Adler, R.; Bolvin, D.; Nelkin, E. The TRMM multi-satellite precipitation analysis (TMPA). In Satellite Rainfall Applications for Surface Hydrology; Gebremichael, M., Hossain, F., Eds.; Springer: Dordrecht, The Netherlands, 2010; pp. 3-22.

24. Yong, B.; Chen, B.; Gourley, J.J.; Ren, L.; Hong, Y.; Chen, X.; Wang, W.; Chen, S.; Gong, L. Intercomparison of the version-6 and version-7 TMPA precipitation products over high and low latitudes basins with independent gauge networks: Is the newer version better in both real-time and post-real-time analysis for water resources and hydrologic extremes? J. Hydrol. 2014, 508, 77-87.

25. Yong, B.; Hong, Y.; Ren, L.L.; Gourley, J.J.; Huffman, G.J.; Chen, X.; Wang, W.; Khan, S.I. Assessment of evolving TRMM-based multisatellite real-time precipitation estimation methods and their impacts on hydrologic prediction in a high latitude basin. J. Geophys. Res. 2012, 117, doi:10.1029/2011JD017069.

26. Huffman, G.J., Bolvin, D.T., Nelkin, E.J., Adler, R.F. Highlights of version 7 TRMM multi-satellite precipitation analysis (TMPA). In Proceedings of 5th International Precipitation Working Group Workshop, Hamburg, Germany, 11-15 October 2010.

27. AghaKouchak, A.; Behrangi, A.; Sorooshian, S.; Hsu, K.; Amitai, E. Evaluation of satellite-retrieved extreme precipitation rates across the central United States. J. Geophys. Res. 2011, 116, doi:10.1029/2010JD014741.

28. Demaria, E.; Rodriguez, D.; Ebert, E.; Salio, P.; Su, F.; Valdes, J. Evaluation of mesoscale convective systems in south America using multiple satellite products and an object-based approach. J. Geophys. Res. 2011, 116, doi:10.1029/2010JD015157.

29. Adler, R.F.; Kidd, C.; Petty, G.; Morrissey, M.; Goodman, H.M.; Einaudi, F. Intercomparison of global precipitation products: The third precipitation intercomparison project (PIP-3). Bull. Am. Meteor. Soc. 2001, 82, 1377-1396.

30. Dinku, T.; Ceccato, P.; Grover-Kopec, E.; Lemma, M.; Connor, S.J.; Ropelewski, C.F. Validation of satellite rainfall products over East Africa's complex topography. Int. J. Remote Sens. 2007, 28, $1503-1526$.

31. Krajewski, W.F.; Ciach, G.J.; McCollum, J.R.; Bacotiu, C. Initial validation of the global precipitation climatology project monthly rainfall over the United States. J. Appl. Meteorol. 2000, 39, 1071-1086.

32. Morrissey, M.L.; Janowiak, J.E. Sampling-induced conditional biases in satellite climate-scale rainfall estimates. J. Appl. Meteorol. 1996, 35, 541-548.

33. Su, F.; Hong, Y.; Lettenmaier, D.P. Evaluation of trmm multisatellite precipitation analysis (TMPA) and its utility in hydrologic prediction in the La Plata basin. J. Hydrometeorol. 2008, 9, 622-640.

34. Tang, L.; Hossain, F.; Huffman, G.J. Transfer of satellite rainfall uncertainty from gauged to ungauged regions at regional and seasonal timescales. J. Hydrometeorol. 2010. 11, 1263-1274.

35. Paola, F.D.; Casella, D.; Dietrich, S.; Mugnai, A.; Ricciardelli, E.; Romano, F.; Sanò, P. Combined MW-IR precipitation evolving technique (PET) of convective rain fields. Nat. Hazards Earth Syst. Sci. 2012, 12, 3557-3570. 
36. Casella, D.; Dietrich, S.; Paola, F.D.; Formenton, M.; Mugnai, A.; Porcu, F.; Sano, P. PM-GCD-A combined IR-MW satellite technique for frequent retrieval of heavy precipitation. Nat. Hazards Earth Syst. Sci. 2012, 12, 231-240.

37. Chokngamwong, R.; Chiu, L.S. Thailand daily rainfall and comparison with TRMM products. J. Hydrometeorol. 2008, 9, 256-266.

38. Cimini, D.; Romano, F.; Ricciardelli, E.; di Paola, F.; Viggiano, M.; Marzano, F.; Colaiuda, V.; Picciotti, E.; Vulpiani, G.; Cuomo, V. Validation of satellite opemw precipitation product with ground-based weather radar and rain gauge networks. Atmos. Meas. Tech. 2013, 6, 3181-3196.

39. Tian, Y.; Peters-Lidard, C.D.; Eylander, J.B.; Joyce, R.J.; Huffman, G.J.; Adler, R.F.; Hsu, K.1.; Turk, F.J.; Garcia, M.; Zeng, J. Component analysis of errors in satellite-based precipitation estimates. J. Geophys. Res. 2009, 114, doi:10.1029/2009JD011949.

40. Abouelmagd, A.; Sultan, M.; Sturchio, N.C.; Soliman, F.; Rashed, M.; Ahmed, M.; Kehew, A.E.; Milewski, A.; Chouinard, K. Paleoclimate record in the Nubian Sandstone Aquifer, Sinai Peninsula, Egypt. Quat. Res. 2014, 81, 158-167.

41. Armanios, D.E.; Fisher, J.B. Measuring water availability with limited ground data: Assessing the feasibility of an entirely remote-sensing-based hydrologic budget of the Rufiji Basin, Tanzania, using TRMM, GRACE, MODIS, SRB, and AIRS. Hydrol. Process. 2014, 28, 853-867.

42. As-syakur, A.; Adnyana, I.; Mahendra, M.S.; Arthana, I.W.; Merit, I.N.; Kasa, I.W.; Ekayanti, N.W.; Nuarsa, I.W.; Sunarta, I.N. Observation of spatial patterns on the rainfall response to ENSO and IOD over Indonesia using TRMM multisatellite precipitation analysis (TMPA). Int. J. Climatol. 2014, 34, 3825-3839.

43. Bin, P.; Shi, J.; ni-Meister, W.; Zhao, T.; Ji, D. Evaluation of TRMM multisatellite precipitation analysis (TMPA) products and their potential hydrological application at an arid and semiarid basin in China. IEEE J. Sel. Top. Appl. Earth Obs. Remote Sens. 2014, 7, 3915-3930.

44. Bitew, M.M.; Gebremichael, M. Evaluation of satellite rainfall products through hydrologic simulation in a fully distributed hydrologic model. Water Resour. Res. 2011, 47, doi:10.1029/2010WR009917.

45. Bitew, M.M.; Gebremichael, M.; Ghebremichael, L.T.; Bayissa, Y.A. Evaluation of high-resolution satellite rainfall products through streamflow simulation in a hydrological modeling of a small mountainous watershed in Ethiopia. J. Hydrometeorol. 2012, 13, 338-350.

46. Getirana, A.; Espinoza, J.; Ronchail, J.; Rotunno Filho, O. Assessment of different precipitation datasets and their impacts on the water balance of the Negro river basin. J. Hydrol. 2011, 404, 304-322.

47. Gosset, M.; Viarre, J.; Quantin, G.; Alcoba, M. Evaluation of several rainfall products used for hydrological applications over West Africa using two high-resolution gauge networks. Quart. J. R. Meteorol. Soc. 2013, 139, 923-940.

48. Jiang, S.; Ren, L.; Hong, Y.; Yang, X.; Ma, M.; Zhang, Y.; Yuan, F. Improvement of multi-satellite real-time precipitation products for ensemble streamflow simulation in a middle latitude basin in south China. Water Resour. Manag. 2014, 28, 2259-2278.

49. Khan, S.I.; Hong, Y.; Gourley, J.J.; Khattak, M.U.K.; Yong, B.; Vergara, H.J. Evaluation of three high-resolution satellite precipitation estimates: Potential for monsoon monitoring over Pakistan. Adv. Space Res. 2014, 54, 670-684. 
50. Lauri, H.; Räsänen, T.; Kummu, M. Using reanalysis and remotely sensed temperature and precipitation data for hydrological modeling in monsoon climate: Mekong river case study. J. Hydrometeorol. 2014, 15, 1532-1545.

51. Lemons, R.; Hewitt, A.; Kharel, G.; New, C.; Kirilenko, A.; Zhang, X. Evaluation of satellite-derived agro-climate variables in the northern great plains of the United States. Geocarto Int. 2012, 27, 613-626.

52. Munier, S.; Aires, F.; Schlaffer, S.; Prigent, C.; Papa, F.; Maisongrande, P.; Pan, M. Combining data sets of satellite-retrieved products for basin-scale water balance study: 2. Evaluation on the Mississippi Basin and closure correction model. J. Geophys. Res. 2014, 119, 12100-112116.

53. Serrat-Capdevila, A.; Valdes, J.B.; Stakhiv, E.Z. Water management applications for satellite precipitation products: Synthesis and recommendations. JAWRA J. Am. Water Resour. Assoc. 2014, 50, 509-525.

54. Siddique-E-Akbor, A.; Hossain, F.; Sikder, S.; Shum, C.; Tseng, S.; Yi, Y.; Turk, F.; Limaye, A. Satellite precipitation data-driven hydrological modeling for water resources management in the Ganges, Brahmaputra, and Meghna basins. Earth Interact. 2014, 18, 1-25.

55. Tong, K.; Su, F.; Yang, D.; Hao, Z. Evaluation of satellite precipitation retrievals and their potential utilities in hydrologic modeling over the Tibetan Plateau. J. Hydrol. 2014, 519, 423-437.

56. Vergara, H.; Hong, Y.; Gourley, J.J.; Anagnostou, E.N.; Maggioni, V.; Stampoulis, D.; Kirstetter, P.-E. Effects of resolution of satellite-based rainfall estimates on hydrologic modeling skill at different scales. J. Hydrometeorol. 2014, 15, 593-613.

57. Voisin, N.; Pappenberger, F.; Lettenmaier, D.P.; Buizza, R.; Schaake, J.C. Application of a medium-range global hydrologic probabilistic forecast scheme to the Ohio River Basin. Weather Forecast. 2011, 26, 425-446.

58. Wu, H.; Adler, R.F.; Hong, Y.; Tian, Y.; Policelli, F. Evaluation of global flood detection using satellite-based rainfall and a hydrologic model. J. Hydrometeorol. 2012, 13, 1268-1284.

59. Zhao, H.; Yang, S.; Wang, Z.; Zhou, X.; Luo, Y.; Wu, L. Evaluating the suitability of TRMM satellite rainfall data for hydrological simulation using a distributed hydrological model in the Weihe river catchment in China. J. Geogr. Sci. 2015, 25, 177-195.

60. Berg, W.; L'Ecuyer, T.; Kummerow, C. Rainfall climate regimes: The relationship of regional TRMM rainfall biases to the environment. J. Appl. Meteorol. Climatol. 2006, 45, 434-454.

61. Seto, S.; Iguchi, T.; Meneghini, R. Comparison of TRMM PR v6 and v7 focusing heavy rainfall. In Proceedings of the 2011 IEEE International Geoscience and Remote Sensing Symposium (IGARSS), Vancouver, BC, Canada, 24-29 July 2011.

62. Pereira, R.; Bovolo, C.I.; Forsythe, N.; Pedentchouk, N.; Parkin, G.; Wagner, T. Seasonal patterns of rainfall and river isotopic chemistry in Northern Amazonia (Guyana): From the headwater to the regional scale. J. South Am. Earth Sci. 2014, 52, 108-118.

63. Huffman, G.J.; Bolvin, D.T. Real-Time TRMM Multi-Satellite Precipitation Analysis Data Set Documentation. 2013. Available online: ftp://meso-a.gsfc.nasa.gov/pub/trmmdocs/rt/ 3B4XRT_doc_V7.pdf (accessed on 20 February 2015).

64. Shahin, M. Water Resources and Hydrometeorology of the Arab Region; Springer Science \& Business Media: Berlin/Heidelberg, Germany, 2007; Volume 59. 
65. Knippertz, P.; Christoph, M.; Speth, P. Long-term precipitation variability in morocco and the link to the large-scale circulation in recent and future climates. Meteorol. Atmos. Phys. 2003, 83, 67-88.

66. El Hamly, M.; Sebbari, R. Towards the Seasonal Prediction of Moroccan Precipitation and Its Implications for Water Resources Management. Available online: http:/hydrologie.org/ redbooks/a252/iahs_252_079.pdf (accessed on 20 February 2015).

67. Huebener, H.; Kerschgens, M. Downscaling of current and future rainfall climatologies for Southern Morocco. Part I: Downscaling method and current climatology. Int. J. Climatol. 2007, 27, 1763-1774.

68. Ward, M.N.; Lamb, P.J.; Portis, D.H.; el Hamly, M.; Sebbari, R. Climate variability in Northern Africa: Understanding droughts in the Sahel and the Maghreb. In Beyond el Niño; Springer: Berlin/Heidelberg, Germany, 1999; pp. 119-140.

69. Chaponniere, A.; Smakhtin, V. A Review of Climate Change Scenarios and Preliminary Rainfall Trend Analysis in the Oum er Rbia Basin, Morocco; International Water Management Institute (IWMI): Colombo, Sri Lanka, 2006; Volume 110.

70. Snoussi, M.; Haïda, S.; Imassi, S. Effects of the construction of dams on the water and sediment fluxes of the Moulouya and the Sebou Rivers, Morocco. Reg. Environ. Chang. 2002, 3, 5-12.

71. World Meteorological Organisation. Guide to Hydrological Practices: Data Acquisition, and Processing, Analysis, Forecasting and Other Applications; World Meteorological Organisation: Geneva, Switzerland, 1994.

72. Grove, A.T.; Miles, M.; Worthington, E.; Doggett, H.; Dasgupta, B.; Farmer, B. The geography of semi-arid lands [and discussion]. Philos. Trans. R. Soc. B 1977, 278, 457-475.

73. UNEP, N.M.; Thomas, D. World Atlas of Desertification; Edward Arnold: London, UK, 1992.

74. Gutierrez, M. Geomorphology; CRC Press: Boca Raton, FL, USA, 2012.

75. Nash, J.E.; Sutcliffe, J.V. River flow forecasting through conceptual models part I-A discussion of principles. J. Hydrol. 1970, 10, 282-290.

76. Moriasi, D.N.; Arnold, J.G.; van Liew, M.W.; Bingner, R.L.; Harmel, R.D.; Veith, T.L. Model evaluation guidelines for systematic quantification of accuracy in watershed simulations. Trans. ASABE 2007, 50, 885-900.

77. Gupta, H.; Sorooshian, S.; Yapo, P. Status of automatic calibration for hydrologic models: Comparison with multilevel expert calibration. J. Hydrol. Eng. 1999, 4, 135-143.

78. Amitai, E.; Llort, X.; Liao, L.; Meneghini, R. A framework for global verification of space-borne radar estimates of precipitation based on rain type classification. In Proceedings of the 2nd TRMM International Science Conference, Nara, Japan, 6-10 September 2004.

79. Fu, Y.; Liu, G. Possible misidentification of rain type by TRMM PR over Tibetan Plateau. J. Appl. Meteorol. Climatol. 2007, 46, 667-672.

80. Romilly, T.; Gebremichael, M. Evaluation of satellite rainfall estimates over Ethiopian River Basins. Hydrol. Earth Syst. Sci. 2011, 15, 1505-1514.

81. Grody, N.C.; Weng, F. Microwave emission and scattering from deserts: Theory compared with satellite measurements. IEEE Trans. Geosci. Remote Sens. 2008, 46, 361-375.

(C) 2015 by the authors; licensee MDPI, Basel, Switzerland. This article is an open access article distributed under the terms and conditions of the Creative Commons Attribution license (http://creativecommons.org/licenses/by/4.0/). 